\title{
EL PROBLEMA DEL ACTOR EN CERVANTES: UNA REVISION DESDE LA PRECEPTIVA NEOCLÁSICA
}

Javier VELLÓN LAHOZ

El investigador teatral que pretenda una aproximación al fenómeno actoral en el Barroco coincidirá con José Manuel Rozas en certificar «la pobreza de testimonios sobre la manera de representar* (193). Pese a la importancia de lo teatral, como noción genérica del arte barroco, la figura que encarna la primera materia para mostrar la obra-sobre todo, en una práctica escénica determinada por la carencia de medios y sostenida por el cuerpo del representante-carece de una preceptiva específica en la época, por lo que, tradicionalmente, nuestro conocimiento acerca de su técnica y costumbres se nutre de fuentes indirectas consultadas hasta la saciedad: relatos costumbristas, tratados fisiognómicos y de pintura, testimonios metateatrales incluidos en las comedias, diatribas de los moralistas, apuntes de oratoria profana y sagrada, etc.

Sin embargo, no se ha cotejado con suficiente atención una vía de acceso históricamente contrastable, capaz de aportar una nutrida información sobre el tema: las teorías sobre declamación dieciochescas -cronológicamente ampliables hasta las primeras décadas del XIX-, tanto en sus formulaciones francoitalianas, como las netamente españolas.

Nombres como Diderot, Riccoboni, Sainte-Albine, Lessing, Claude-Joseph Dorat, junto a los de grandes actores -especialmente franceses-, se asocian a la especulación sobre los métodos actorales en un siglo en el que, como indica Franco Ruffini, la reflexión teatral adopta una dimensión filosófica: «Come 
conciliare l'esistenza del «comédien» con la premessa teorica riguardante l'uomo in generale? × (85). La nueva consideración social y cultural del oficio actoral acaba con los prejuicios teológicos que estaban en el origen de la discriminación del XVII ( el ser capaz de mudar su cuerpo, según las conveniencias, transgrediendo el orden impuesto por la divinidad). Síntoma de juicios favorables es la profusión de retratos de actores célebres que, como señala Maria Ines Aliverti, "ciò accade contemporaneamente all"intersificarsi delle biographie e degli scrit autobiografici» (22-23).

La situación en España es similar, con las salvedades propias del neoclasicismo peninsular: Luzán traduce, en el capítulo XI de sus Memorias literarias de París (1751), un fragmento de El arte del teatro de François Riccoboni; J. D. M. hace lo propio con las Reflexiones de Mma. Clairon (1800), el mismo año en que aparece la traducción de Santos Díez y Manuel de Valbuena del arte de declamación de Lauriso Tragiense. Pero será a partir del influjo aportado por el genio de Isidoro Máiquez cuando los tratados sobre el actor comienzan a tener una incidencia real, con las obras de Félix Centrillón, Vicente Joduuín Bastús, Andrés Prieto, Carlos Latorre, etc.

Las propuestas de la teoría actoral hispana, en pro de $\alpha$ la medida exacta -en palabras de Jesús Rubio (270)-, entre la naturalidad y el artificio, poseen una singularidad que las convierte en ilustrativas para el interés del presente artículo: ante la pervivencia de procedimientos declamatorios anclados en la tradición barroquista -perpetuados a través del éxito de la "comedia de espectáculo» dieciochesca y no de la limitada popularidad del teatro barroco, como ha demostrado René Andioc (31 y ss.) y Donald C. Buck-, la preceptiva española vuelve una y otra vez sobre los defectos históricos del cómico nacional, contraponiendo las nuevas modalidades que tienden a consolidarse. Desde esta disposición crítica, las alusiones desplegadas por los dramaturgos barrocos cobran relevancia al ser contrastadas con un aparato teórico del que carecían en su época, y ofrecen luz sobre aspectos no siempre entendidos en su exacto contexto.

La afición de Cervantes por el teatro ha sido convenientemente resaltada por la crítica, afición que se trueca en resignación, cuando no amargura, ante el escaso éxito obtenido en su faceta de dramaturgo, pese a asumir los planteamientos de la ucomedia nueva lopesca. A lo largo de su obra no desperdició ocasión de teorizar sobre importantes cuestiones teatrales: los capítulos dedicados al particular en el Quijote, en el Viaje del Parnaso, la Jornada II de El rufián dichoso, el prólogo a sus Ocho comedias y entremeses, en alguna de sus Novelas ejemplares e, incluso, en un alarde que demuestra unos conocimientos que 
abarcan los distintos géneros dramáticos, su aproximación a formas marginales y caracteres de la tradición como el entremés El rufián viudo.

Sus personajes testimonian una experiencia sobre el mundo de la farándula que apunta directamente a la propia vivencia de su creador, lo que contribuye a dar relevancia a sus opiniones sobre el tema. Don Quijote no duda en afirmar que «desde muchacho fui aficionado a la carátula, y en mi mocedad se me iban los ojos tras la farándula» (II, cap. 11, 175); en parecidos términos se expresa el gobernador de El retablo de las maravillas: "pícome de la farándula y carátula» (174); Madrigal, en La gran sultana, anhela volver a España para hacerse comediante "y componer la historia de esta niña/... / representando el mismo personaje/ allá que hago aquí» (488).

La primera cuestión sobre los actores se relaciona con la conocida opinión que, durante el seiscientos, merecían sus costumbres irregulares, su vivencia al margen de los imperativos sociales y que, en definitiva, viene determinada por la rigidez de una cultura conservadora que condena al cómico moralmente, pero le admira como exponente de la teatralidad. En El coloquio de los perros, Berganza relata a Cipión sus experiencias con una compañía:

"vi desta gente su proceder, su vida, sus costumbres, sus ejercicios, su trabajo, su ociosidad, su ignorancia y su agudeza, con otras infinitas cosas, unas para decirse al oído y otras para aclamallas en público, y todas para hacer memoria dellas y para desengaño de muchos que idolatran en figuras fingidas y en bellezas de artificio y de transformación.»(II, 354)

Discriminación social que, paradójicamente, se suma a una cierta invulnerabilidad frente a las leyes pues, como afirma Sancho: «como son gentes alegres y de placer, todos les favorecen, todos los amparan, ayudan y estiman» (II, cap. 11, 178).

Esta primera consideración posee una gran transcendencia en la evolución del arte escénico, con mención especial para el caso español. La aceptación social del actor, en el siglo XVIII, acarrea una serie de consecuencias en el ámbito estrictamente teatral: éste ha de plegarse a un nuevo modelo de declamación, fruto de una laboriosa instrucción en la preceptiva racionalista, por los que «reune en sí el mérito del orador, del pintor, y en una palabra de una porción de artistas», como indica J. D. M. en el prólogo a su traducción de las Reflexiones de Mma. Clairon (8).

La integración social del actor suponía, ante todo, la necesidad de doblegarse a los requisitos reformistas de la política ilustrada, cuyos más notables representantes en el dominio teatral, en su tarea de regularizar el circuito de la 
producción teatral, prescriben la conveniencia de crear centros formativos con el fin de canalizar la declamación hacia las exigencias estéticas del programa neoclásico.

Sin embargo, los hábitos de los actores españoles están lo suficientemente arraigados desde el Siglo de Oro para dificultar el empeño renovador. Desde el siglo XVI se proyecta la idea corporativista de que la experiencia gremialista es la única escuela, transmitida a través de una tradición -básicamente familiarque es reacia a la «artificiosidad» de los métodos educativos franceses. «Ignorancia» y «agudeza», los calificativos expuestos por Berganza, son las constantes asociadas al cómico nacional, remiso a aceptar innovaciones tendentes a la naturalidad expresiva, y predispuesto a la vitalidad de la improvisación, en una actitud de intercomunicación directa con el público. Una situación que lleva a J. D. M. a denunciar que «aquí los cómicos no tienen una idea fixa de lo que es su arte, ni un método regular para adquirir esa idea* (204).

En estrecha relación con dicha identificación del colectivo actoral está la acusación que Cervantes pone en boca del canónigo de Toledo en su erudito razonamiento con el cura en el Quijote (I, cap. 48):

«Y aunque algunas veces he procurado persuadir a los actores que se engañan en tener la opinión que tienen, y que más gente atraerán, y más fama cobrarán representando comedias que hagan el arte que no con las disparatadas, y estár tan asidos y encorporados cn su parecer, que no hay razón ni cvidencia que dél los saque...Asi que no está la falta en el vulgo que pide sus disparates, sino en aquellos que no saben representar otra cosa» (912).

Una primera lectura de tales palabras nos conduce al conocido escepticismo cervantino por el escaso eco de sus piezas, y al reproche a ese «mi maldiciente autor" que, sin ambigüedades, cita en el prólogo a Ocho comedias y entremeses: "que no hallé autor que me las pidiese, puesto que sabían que las tenía (210). Se trata de su defensivo rechazo a todos los integrantes de la profesionalidad teatral -actores, empresarios, compañías- y la velada acusación a la popularidad del teatro de Lope quien "puso bajo su jurisdicción a todos los farsantes».

No me interesa, sin embargo, resaltar esta vertiente de la crítica cervantina, sino un aspecto de su juicio que encuentra cumplida respuesta en las formulaciones posteriores de los informes para la reforma del espectáculo dieciochesco, herederas directas de las recriminaciones del autor del Quijote.

Desde Lope de Vega, con su síntesis «el gusto/lo justo», ese «monstruo informe» que es el vulgo carga con la responsabilidad de las transformaciones de la poética clásica en el paradigma de la tragicomedia. La dinámica de tal 
populismo fructifica en cada uno de los sectores ligados a la teatralidad, no sólo en los poetas -acogidos al ideario lopesco-, sino sobre todo en los cómicos, cuya vinculación con el auditorio les hace más receptivos a sus propuestas.

Dado que la historia teatral se ha confeccionado, habitualmente, en función de los dramaturgos, no se ha estudiado en profundidad la relevancia de ciertos actores en la consolidación de los métodos declamatorios. Los intelectuales del XVIII, sesudos intérpretes de la potencialidad formativa del teatro, se percataron muy pronto de la contribución de los representantes en la perpetuación de un determinado horizonte de expectativas en los auditorios. Juan Pablo Forner en La escuela de la amistad o el filósofo enamorado incide en este aspecto del problema señalando que:

"Quando el estupendo Lope de Vega osó afirmar en su Nuevo Arte de escribir comedias sin arte, que para agradar al pueblo en las representaciones del Teatro, era preciso desnudarlas de toda regularidad, y dexarlas entregadas enteramente al capricho e imaginación desenfrenada de los Poetas; no parecía que quiso decir otra cosa, sino que el vulgo ha recibido la racionalidad sólo por amar los despropósitos y admirar las extravagancias...jPobre vulgo! Los comicastros cargan sobre él la culpa de su propia incapacidad» (196).

Más incisiva es la diatriba de Cándido María Trigueros en el prólogo de su Teatro español burlesco, dedicado "a los comediantes de uno y otro sexo, y sus fautores y apasionados», recriminándoles en los siguientes términos:

«En estas circunstancias me aprovecho del encargo de escribir esta dedicatoria, para suplicarles rendidamente que por el amor de su patria se corran y avergüencen de haber hecho que se corrompa el teatro, sostenido y fomentado el mal gusto del vulgo, y puesto INCESAMENTE nuevos obstáculos a la reforma que necesita este precioso ramo de nuestra literatura. Si vms. se corren y se enmiendan conoceré y publicaré que son racionales, útiles y sanos; pero si no se avergiienzan, quedarán vms. condenados a ser perpetuados Crispines* $(x i x-x x)$.

Los argumentos de Forner están dirigidas a la responsabilidad de los dramaturgos en la pervivencia de un espectáculo efectista, derivación manierista del concepto de la dramaturgia barroca; las de Trigueros a los intérpretes que, según parecer de los neoclásicos, tiranizan el circuito teatral, convirtiéndose en jueces interesados de la confección de los repertorios, y defensores de una práctica ajena a la vertiente naturalista de las nuevas doctrinas dramáticas.

Tanto en Cervantes como en los autores mencionados subyace un factor determinante en la historia del teatro: el público. Desde la acepción «vulgo», a la que eran tan proclives los preceptistas del seiscientos, hasta la noción de «es- 
pectador", habitual entre los tratadistas dieciochescos, existe toda una corriente de la filosofía social que se manifiesta directamente en la consolidación de los sistemas dramáticos, tal como reconocen Monne Z. Hafter, Pedro Alvarez de Miranda y Natividad Massanés.

En los informes sobre la reforma teatral -los de Bernardo de Iriarte, Jovellanos, Leandro Fdez. de Moratín, Santos Díez- sc pretende operar una selección de los auditorios -arguyendo, incluso, la necesidad de ajustar los precios de las localidades al alza- en la que se refleja una renovadora visión del espectador acorde con la perspectiva social, y con lá clase media como referente cultural. De la "masa informe»-correlato del "vulgo»- se pasa a la idea de «ciudadanos», noción sujeta a la idea de Estado y, más tarde, derivada de la comunidad de intereses que se integra bajo el espíritu de nación, históricamente conformado.

La disposición de la recepción en los coliseos, en lo que Enrique Funes definió como wel arte del silencio" (504), posibilita la difusión de una estética teatral con marcadas diferencias respecto a la del XVII. I. I. Mccllelland y Joaquín Alvarez Barrientos insisten en la transcendencia de esta transfornación de la sociología teatral para explicar la distancia entre dos modalidades escérnicas: la que conoció Cervantes, cuya herencia se proyecta hacia la cornedia de "gran espectáculo» dieciochesca, en la que predomina una comunicación entre escenario y auditorio, en una concepción aristotélics y participativa, con cscasos paréntesis para la autoafirmación de la teatralidad, reservadas al gracioso, como indica Rozas; por su parte, el teatro de la ilusión referencial, plantcado sobre la conciencia del distanciamiento brechtiano, dirigido a la expresión sentimental y a provocar la complicidad anímica del espectador.

I La figura de] actor en una y otra práctica escénica se abre a diferentes estrategias. La que defiende Cervantes, postura remarcada en textos que veremos a continuación, se funda en una concepción del espectáculo próxima a los postulados de los teóricos teatrales neoclásicos, al margen de los condicionamientos ideológicos de las dos épocas históricas.

I a conciencia profesional del cómico -en términos fornativos- exige unáa disposición particular del espacio de la representación y una actitud de distanciamiento *ilusorio» por parte del espectador', en terminología de José M." Azpitarte. El ideal declamatorio, personificado por Máiquez, ha de renunciar tanto al histrionismo artificioso de la tradición barroquista española -más dirigida a la connivencia del espectador que a la recreación de una ficción escénica (defecto común de los actores españoles, pues como señala Enrique 
Funes, "hasta la venida de Máiquez no empieza a suprimirse el auditorio» $(480)$ ) -, como al «sermoneo soporífero" (Funes (481)) del clasicismo galo expuesto por Diderot.

El prototipo actoral debe basarse, en primer lugar, en la evidencia de la ilusión referencial: *el actor es hombre perdido si cuando habla olvida que está fingiendo», recuerda Bretón de los Herreros (10). Una vez cumplido dicho requisito, el cómico ha de conseguir compatibilizar el patetismo expresivo de una situación trágica con una valoración del efecto causado sobre la emotividad del auditorio. La finalidad última es conseguir una declamación natural, cercana a la experiencia del espectador, puesto que, como indica José de la Revilla -el más importante tratadista del arte de Máiquez-, «el teatro debe ser imagen exacta de la sociedad, y que los personajes en él introducidos han de hablar, moverse y gesticular como los demás hombres\$ (22). En definitiva, una difícil síntesis entre la modulación «delicada, dulce y tierna, al par que noble, majestuosa y terrible».

La gran revolución propiciada por Máiquez exigía un repertorio que se acomodara a sus propuestas. Lo va a encontrar, como recuerda Bretón de los Herreros, en unos textos que se ajustan a la línea analítica seguida en el presente artículo: las piezas del Siglo de Oro -destacó en los papeles de García del Castañar, y otros similares- refundidós según las normas neoclásicas por su amigo y colaborador Dionisio de Solís, sin olvidar la contribución decisiva del empresario y director Grimaldi. La fuerza de los personajes ideados por Calderón, Moreto o Rojas Zorrilla se canaliza a través de una versión dirigida por el ideario neoclásico, en una tarea de asimilación de la tradición nacional con las formas del realismo y del sentimentalismo. Sin duda Máiquez haría suyas las palabras de Cervantes en el prólogo a sus Ocho comedias...: "fui el primero que representase las imaginaciones y los pensamientos escondidos del alma».

Pero el texto cervantino más importante sobre el actor es el que aparece en la Jornada II de su comedia Pedro de Urdemalas, a través del relato de su protagonista:

* Sé todo aquello que cabe en un general farsante; sé todos los requisitos que un farsante ha de tener para serlo, que han de ser tan raros como infinitos.

De gran memoria, primero; segundo, de suelta lengua, y que no padezca mengua 
de galas es lo tercero.

Buen talle no le perdono,

si es que ha de hacer los galanes;

no afectado en ademanes, ni ha de recitar con tono.

Con descuido cuidadoso, grave anciano, joven presto, enamorado compuesto, con rabia si está celoso. Ha de recitar de modo. con tanta industria y cordura, que se vuelva en la figura que hace de todo en todo. A los versos ha de dar valor con su lengua experta, y a la fábula que es muerta ha de hacer resucitar. Ha de sacar con espanto las lágrimas de la risa, y hacer que vuelvan con prisa otra vez al triste llanto.

Ha de hacer que aquel semblante que él mostrare, todo oyente le muestre, y será excelente si hace aquesto el recitante.» (654)

En primer lugar Cervantes refiere cuestiones que afectan al dominio escénico del actor y al aprendizaje de una técnica capaz de uhacer desaparecer a los ojos del espectador el arte que empleaban en sus respectivos papeles», en palabras de Bretón de los Herreros ( $₫$ Diferentes sistemas... (117-118) ).

Ocupa un lugar destacado el estímulo de la memoria, condición indispensable para *la suelta lengua*. Todos los tratadistas neoclásicos insisten en criticar una costumbre arraigada en el cómico español: la dificultad de aprender los papeles, por razones de premura, con calendarios sobrecargados para las compañias que les impedía ensayar con detenimiento las piezas. Esto suponía, bien la constante improvisación, bien, en los coliseos dieciochescos, la dependencia de los apuntadores, lo que iba en perjuicio de la naturalidad en la elocución.

Estas aseveraciones apuntan a la exigencia de un nuevo concepto sobre el actor: éste debe ser consciente de la importancia de su actividad, incluida entre las manifestaciones artísticas, lo que implica una sólida formación que le lleve a una constante "práctica y estudio, para olvidar su propio ser, para identificarse con el de las personas que existen, han existidow, como aconseja Andrés Prieto. La falta de un conocimiento profundo de la naturaleza humana com- 
porta un tipo de representación pendiente del público, y sin un compromiso escénico con el personaje. La memoria requiere, ante todo, una apuesta por la expresividad natural, y por un análisis de los caracteres que sólo puede provenir del ensayo y de la voluntad creativa del actor.

A continuación, y tras referirse a la constitución física, aconseja que el actor no sea "afectado de ademanes/ ni ha de recitar con tono", sugerencia desarrollada en versos posteriores ( $\mathrm{Ha}$ de recitar de modo...»).

Este punto es uno de los cruciales en la historia de la teoría actoral, pues, además de incidir en la consideración en torno al atributo de la voz, se dirige a la problemática del verso frente a la prosa en las preceptivas teatrales españolas.

El debate se centra en los siguientes factores:

-El teatro barroco encuentra en el verso su canal adecuado de expresión, y la polimetría es un medio con funcionalidad escénica, de manera que el actor del XVII cuenta con al musicalidad, rima, ritmo, tanto con una finalidad mnemotécnica como declamatoria, tal y como ha sido puesto de relieve por estudiosos como Diego Marín o José Antonio Maravall, quien habla de la * acción martilleante de los versos, vehículo de unas fórmulas de aceptación acrítica ( sociedad barroca $\ldots \curvearrowright(37))$.

Sin embargo, desłe una óptica clasicista - por la que opta el purismo cervantino-la declamación versal incurre en un exceso expresivo, por el que los cómicos pretenden estimular las reacciones afertivas de un autitorio escasamente receptivo a los complejos retoricismos del contenido: la grandilocuencia y el destordamiento ocapan el lugar de la naturatidad, de modo que la inteligibilidad del mensaje se suhordina a los recursos conativos utilizados por el actor para mantener viva la atención de un público heterogéneo. De ahí que Carvantes, en su Adjunta al Parnaso, anuncie la intención de editar sus comedias, ya que ano se entienden cuando las representan (121).

- La reacción ante esta tradición declamatoria española -que mantiene su vigencia durante el setecientos- pretende demostrar que "no hay sensibilidad sin pormenores, como dice Andrés Prieto, y que ael que juzgue provocar la sensibilidad con vocis y viofentos eqfurzos nunca lo conseguirás, apostilla el citado crítico.

Sin embargo la solución a la disyuntiva planteada por Cervantes dista de ser fácil en las polémicas teatrales neoclásicas.

Por una parte la declamación en verso se asocia con una tradición afectada, histriónica, centrada en la exposición verbal que persigue el efectismo auditivo más que la claridad en la elocuencia. Por otra parte, el modelo francés anteponía el texto "hablado» al "declamado"-como recuerda Enrique Funes e, implícitamente, Mme. Clairon-, sintoma de la preeminencia concedida a la naturalidad y 
al realismo escénico. Andrés Prieto aporta la siguiente opinión, fundamentada en el método de Máiquez:

* Muchas personas agitau la cuestión de si la tragedia debe ser hablada o declamada, pero es muy cierto que Calderón, Cervantes, Lope, Moratín, Molière, Racine, Corneille no han hecho sus exquisitos versos para que los reduzcan al tono prosaico."

De nuevo, como manifestación de una estética genérica que opta por el compromiso del "justo medio" -correlato de la política de consenso seguida durante los inicios del XIX- la teoría dramática se inclina por un tono declamatorio "pero de manera que se pueda decir que la hablaba con dignidad. scintencia Prieto.

La vinculación entre el paradigma harroco -aceptado como exponente de un nacionalismo cada vez más prescnte en el discurso de los ueoclásicos finiseculares- y el sistema rucionalista, encuentra en España sus más firmes defensores. Como tributo a una filosofía historicista, el germen del romanticismo conservador - cuyo adalid es Lista- reivindica el pasado cultural, si bien a través de una interpretación racionalista, cuyos resultados más evidentes son las piezas refundidas por Trigueros y sus continuadores (Solís, Bretón. Arellano, etc.).

Cervantes recuerda que el actor dehe dar vida a los versos ( A los versos ha de dar valor...»), lo que implica una conciencia lúcida capaz de distinguir el texto literario del texto espertacular. A su vez, supone una decidida apuesta por el valor dramático del verso como mecanismo privilegiado para el necesario distanciamiento, esto es, para crear la ficción realista, reflejo de toda dramaturgia que intente inwidir en la voluntad intelectiva y sentimental del auditorio.

Sobre el actor recae la responsabilidad primera de «hacer resucitar» una propuesta literaria y convertirla en acto teatral; esto significa que la unidad de interés -la que cataliza la atención de las preceptivas en las postrimerías del XVIII- es, ante todo, un signo de teutralidad y no una meru especulación erudita.

La función educadora adcl teatro, perfectamente descrita por José Antonio Maravall ( La función educadora,...). argumento clave en los proyectos reformistas, exige un cambio en los planteamientos formulados desde la ahstracción: dicha utilidad no puede cumplirse desde el esquematismo de un prosaimo racionalista, sino a través de la tonalidad sentimental, a partir de un teatro que, sin renunciar a unos límites consagrados por le componente clasicista, se abra a la evocación emocional. Es el "racionalismo sentimental» del que hábla Eva 
Kahilhuoto, y cuya expresión escénica ha de ser asumida por el cómico. Los últimos versos de la cita de Cervantes apuntan hacia esa disposición del actor: su preparación ha de guiarse por un aprendizaje de las «reglas del arte», pero sin someterse totalmente a ellas, y por un estudio de la sensibilidad humana -Prieto cita a Condillac como modelo- que le induzca a «dejarse arrebatar", como indica el mismo autor.

Russell P. Sebold ha demostrado convincentemente los vínculos entre el humanismo español del quinientos, el neoclasicismo, e, incluso, el romanticismo como derivación del sistema filosófico dieciochesco. Cervantes es, sin duda, uno de los autores más admirados en su vertiente como intelectual proclive a proclamar su interés por los problemas del corazón humano sin, por ello, desdeñar un talante riguroso, analítico, racional en suma, en la observación de la naturaleza y en la reflexión sobre principios estéticos.

El teatro cervantino no logró la repercusión pública del teatro lopesco, pero sus juicios sobre un tema tan controvertido como es el oficio actoral reflejan una poderosa intuición escénica, descrita con un cierto escepticismo, aunque caracterizada por una proverbial anticipación de lo que serán los debates dramáticos en los umbrales del movimiento romántico.

\section{OBRAS CITADAS}

ALIVERTI, María Inés: 1 ritratto d'attore nel Settecento francese e inglese. Pisa, ETS Editrice, 1986.

ALVAREZ BARRIENTOS, Joaquín: «El actor español en el siglo XVIII: formación, consideración social y profesionalidad». Revista de literatura, julio-diciembre 1988 , t. L, nº 100, págs. 445-465.

ALVAREZ DE MIRANDA, Pedro: -Una voz tardia incorporada a la lengua: la palabra *espectador' en el siglo XVIIV. Coloquio internacional sobre el teatro español del siglo XVIII (Bolonia, 1985).Bolonia, Abano Terme, 1988, págs. 45-66.

ANDIOG, René: Teatro y sociedad en el Madrid del siglo XhIII. Valenciu, Fundación Juan March y Editorial Catalia, 1976.

AZPITARTE, José M. ${ }^{a}$ : «La ihusión escénica en el siglo XVIII». Cuadernos Hispanoamericanos, 1975, 303, págs. 657-675.

BRETON DE LOS HERREROS, M.: Progresos y estado actual del arte de la declamación en los teatros de España. Madrid, Establecimiento tipográfico de Mellado, 1852. 
Difereums siatemas de los acares para la representación de los dramas». Correo liverarî y mercuntil (5-LX-1831), artículos recogidos en Díez Taboada y José Manuel Rozas, Mamiel Bretón de los Herreros. Obra disper'sa, Logroño, Instituo de estudios rojanos, 1965 , págs. 117-118.

BLCCK, Donald C.: «Pedro Calderón de la Barca and Madrid's theatrical calendar, 1700-1750: a question of prioritiesx. Theatre survey, 1984, 25, 1, págs. 69-81.

CERVANTES, Miguel de: Novelas ejemplares, ed. de Harry Sieber, Madrid, Cátedra, 1980.

Entremeses, ed. de Eugenio Asensio, Madrid, Castalia, 1981.

Don Quijote de La Mancha, ed, de Vicente Gaos, Madrid, Gredos, 1987.

Obras completas, ed de Angel Valbuene Prat, Madrid, Aguilar, 1992, vol. I.

CLAIRON, Hipólite: Reflexiones de Mma. Clairon, actriz del teatro de la comedia francesa, sobre el arte de la declamación, traduce, de J. D. M. Madrid, Oficina de Cerónimo (htegga, 1800.

FORNER, Iuan Pablo: Obras completas. Madrid, 1952, BAt, wol. LXIII.

FUNES, Enuique: La declamación española. Sevilla, Tipografía de Díaz y Carballo, 1894.

HAFTER, MONROE Z.: "Ambigủedad de la palabra "públicon en el siglo XVIII» NRFH 1975, XXIY, págs. 46-63.

KAHILUOTO, Eva M.: “Lo prerromántico. Una variante neoclásica en la estética y literaturas españolas» Iberomanía, 1982, 15, púgs, 47-69.

MARAVALL, José Antonio; "Sociedad barroca y conedia española II Jornada de teatro clásico español. Almagro 1979. Madrid, Ministerio de Cultura, 1980, págs. 35-60.

"La función educadoxa del teatro en el siglo de la Ilustración" Estudios de la historia del pensamiento español siglo XVII. Madrid, Mondadori, 1991, págs. 382-405.

MARIN, Diego: *Función dramática de la versificación en el teatro de Cialderón* Segismundo (1982), 35-36, págs. 95-113.

MASSANES, Natividad: «Auditorio, pueblo, vulgo: el espectador en la crítica dramática del siglo XVIII español» Estudios escénicos (1975), 19, 83-101.

McCLELLAND, I. L.: «The Ejghteenth-century conception of the stage and Histrionic tecniquen. Homenaje a Archer M. Huntington. Wellesley, Mass. 1952, págs. 392 425.

PRIETO, Andrés: Teoría del arte cómico y elementos de oratoria y declamación pura la enseñanza de los alumnos del Real Consenatorio de María Cristina, 1835, B. N., Ms. 2804, s.n.

RE VILLA, José de la: Vida artística de don Isidoro Máiquez, primer actor de los teatros de Madid. Madrid, Imprenta de Miguel Burgos, 1845.

ROZAS, Juan Manuel: «Sobre la técnica del actor barrocon. II Jomadas de tentro clásico español. Almagro, 1979 op. cil., págs. 191-202. 
RUBIO, Jesús: «El realismo escénico a la luz de los tratados de declamación de la época» VV. AA. Realismo y naturulismo on Espriña tn al segunda mitad del siglo XIX, coord. Yvan Lissorgues, Barcelona, Anthropos, 1988, págs. 257-285.

RUFFINI, Franco: «Spessore aila storia: problemi degli attori e problematica sull'attore nel Settecento* Quaderni di teatro. Il teatro dell'illuminismo, febbraio, 1981, 11, págs. 73-89.

SEBOLD, Russell P.: «Romanticismo y Barroco», en Trayectoria del romanticismo español Barcelona, Crítica, 1983, pp.43-73.

TRIGUEROS, Cándido $\mathrm{M}^{\mathrm{a}}$ : Teatro español burlesco o Quixote de los teatros. Madrid, Imprenta de Villalpando, 1802. 